\title{
GESTÃO DA INOVAÇÃO EM ORGANIZAÇÕES: UM ESTUDO DE CASO EM UMA EMPRESA DE PEQUENO PORTE NO SEGMENTO METALÚRGICO NA CIDADE DE CURITIBA -PR
}

\author{
J. MELLO ${ }^{1}$, W. L. S. MARTINS ${ }^{2}$, C. R. VAZ ${ }^{3}$, A. C. FRANCISCO ${ }^{4}$ e P. M. SELIG $^{5}$ \\ ${ }^{1}$ Universidade Federal do Rio Grande do Norte - UFRN \\ ${ }^{2}$ Instituto Federal do Rio Grande do Norte - IFRN \\ 3,5 Universidade Federal de Santa Catarina - UFSC \\ ${ }^{4}$ Universidade Tecnológica Federal do Paraná - UTFPR \\ mellojosi@hotmail.com ${ }^{1}$; wluizmartins@ig.com ${ }^{2}$; karollrvaz@gmail.com ${ }^{3}$; acfrancisco@gmail.com ${ }^{4}$; \\ selig@ufsc.br ${ }^{5}$
}

Artigo submetido em abril/2013 e aceito em junho/2013

\section{RESUMO}

Este artigo apresenta um estudo realizado em uma empresa de pequeno porte no segmento metalúrgico em Curitiba Paraná, com o objetivo de diagnosticar a gestão da inovação neste espaço, utilizando a ferramenta: Octógono da inovação, levando em consideração oito dimensões: liderança, funding, processo, estrutura, pessoas, cultura, estratégia e relacionamentos. A abordagem metodológica utilizada neste artigo caracteriza-se, quanto à natureza: como uma pesquisa aplicada; quanto à abordagem do problema: pesquisa quantiqualitativa; quanto aos objetivos: exploratória e descritiva e quanto aos procedimentos técnicos: pesquisa bibliográfica e estudo de caso. Como resultado deste estudo, constatou-se que embora a empresa reconheça a importância da inovação para a sua manutenção e expansão no mercado, no momento esta está focada em desenvolver sua infra- estrutura, investindo, assim $15 \%$ de sua receita líquida na compra de máquinas, ferramentas e equipamentos mais sofisticados, na ampliação da área para fabricação e armazenagem de materiais e em campanhas publicitárias. A inovação vem em segundo plano, como se pode verificar, que a empresa em questão está buscando parcerias, novos sócios e apoio financeiro em órgãos governamentais, vislumbrando desenvolver projetos de inovação a curto, médio e longo prazo. Diante disso, sugere-se que a empresa estudada contrate um engenheiro de produção para desenvolver um programa de gestão da inovação, reestruturando os processos, reduzindo custos e melhorando a produtividade, fazendo com que esta se torne mais competitiva, aumentando as negociações e empregabilidade, obtendo melhores resultados e aumentando sua fatia no mercado metalúrgico.

PALAVRAS-CHAVE: Gestão da inovação, Empresa de Pequeno Porte, Empresa Metalúrgica.

\section{INNOVATION MANAGEMENT IN ORGANIZATIONS: A CASE STUDY IN A SMALL COMPANY IN BUSINESS IN THE CITY OF METALLURGICAL CURITIBA-PR}

\section{ABSTRACT}

This paper presents a study of a small business in the metallurgical sector in Curitiba - Paraná, in order to diagnose the management of innovation in this space, using the tool: Octagon innovation, taking into account eight dimensions: leadership, funding, process, structure, people, culture, strategy and relationships. The methodological approach used in this article is characterized regarding its nature: as an applied research; regarding the approach to the problem: search quantiqualitative; regarding goals: exploratory, descriptive and technical procedures as: literature review and case study. As a result of this study, it was found that although the company recognizes the importance of innovation for its maintenance and expansion in the market at the moment this is focused on developing its infrastructure, investing, so $15 \%$ of its net income in purchasing machinery, tools and more sophisticated equipment, to expand the area for manufacturing and storage of materials and advertising campaigns. The innovation comes in the background, as can be seen, that the company in question is seeking partnerships, new members and financial support to government agencies, glimpsing develop innovation projects in the short, medium and long term. Therefore, it is suggested that the company hire studied a manufacturing engineer to develop a program of innovation management, restructuring processes, reducing costs and improving productivity, causing it to become more competitive, increasing employability and negotiations, obtaining better results and increasing its market share metallurgist.

KEYWORDS: Innovation Management, Small Business, Metallurgical Company. 


\section{GESTÃO DA INOVAÇÃO EM ORGANIZAÇÕES: UM ESTUDO DE CASO EM UMA EMPRESA DE PEQUENO PORTE NO SEGMENTO METALÚRGICO NA CIDADE DE CURITIBA -PR}

\section{INTRODUÇÃO}

A palavra que melhor define o paradigma atual é, sem dúvida, inovação, pois diante do cenário atual, de acirradas competições entre as empresas, o desafio já não consiste mais em buscar meios para "sobreviver" no mercado, é preciso ir além: "planejar o futuro".

Para planejar o futuro, as empresas precisam ter capacidade de inovar, de se reinventar, de criar oportunidades, visando à liderança em seu ramo de atuação, garantindo assim, seu espaço no mercado a médio e longo prazo.

Uma gestão de inovação tecnológica pressupõe um direcionamento, um sistema de gerenciamento, alguns objetivos, planos e ações que são na verdade função de um administrador e ao mesmo tempo pressupõem a necessidade de conhecimento estratégico da organização, bem como seus pontos fortes e fracos do ponto de vista técnico (MANÃS, 2001).

A indústria metalúrgica vem representando uma importância acentuada para a economia mundial nos últimos anos, proporcionando um aumento considerável nos negócios e na empregabilidade.

Sabe-se também que, a indústria metalúrgica está passando por um processo de reestruturação, que visa reduzir os custos e melhorar a produtividade do trabalho. Tudo isso só está sendo possível graças à introdução da inovação no desenvolvimento de novas aplicações.

Sob esta ótica, o presente artigo tem por objetivo diagnosticar a gestão da inovação em uma empresa de pequeno porte no segmento metalúrgico na cidade de Curitiba, no Estado do Paraná, utilizando a ferramenta: Octógono da inovação, levando em consideração oito dimensões: liderança, funding, processo, estrutura, pessoas, cultura, estratégia e relacionamentos.

A abordagem metodológica utilizada neste artigo caracteriza-se, quanto à natureza: como uma pesquisa aplicada; quanto à abordagem do problema: pesquisa qualitativa; quanto aos objetivos: exploratória e descritiva e quanto aos procedimentos técnicos: pesquisa bibliográfica e estudo de caso.

O presente artigo esta estruturado em mais quatro seções além desta introdução. A segunda seção trata da fundamentação teórica e aborda o tem de inovação, trazendo suas definições, tipos e práticas. A terceira seção apresenta os procedimentos metodológicos aplicados nesta pesquisa. A quarta seção mostra os resultados alcançados. E por último traz as considerações finais.

\section{INOVAÇÃO: CONCEITOS}

Para apresentar o rol de conceitos existentes na literatura sobre inovação, faz-se necessário, primeiramente, fazer uma distinção entre inovação e invenção, pois muitas vezes, essas palavras são entendidas como sinônimos pela sociedade.

Assim, de acordo com Montanha Junior et al (2008, p.2), o que diferencia uma inovação de uma invenção, é que para ser inovação esta precisa ser "percebida e aceita pelos clientes da 
empresa". Ou seja, a simples "introdução de uma novidade em um mercado não caracteriza inovação" (MONTANHA JUNIOR et al, 2008, p.2).

Para o economista austríaco: Schumpeter o que diferencia a inovação da invenção é o fato de a primeira estar vinculada a um ganho econômico. Para este economista, a inovação tem o papel fundamental de impulsionar o progresso econômico por meio do progresso técnico (SCHERER E CARLOMAGNO, 2009).

Assim, baseado no economista austríaco, vários autores foram desenvolvendo, ampliando ou restringindo o conceito de inovação, conforme apresentados no quadro 1, a seguir:

Quadro 1: Conceitos de inovação

\begin{tabular}{|l|l|}
\hline \multicolumn{1}{|c|}{ AUTOR(S) } & \multicolumn{1}{|c|}{ CONCEITO DE INOVAÇÃO } \\
\hline Van de Ven et al. (1989) & $\begin{array}{l}\text { É um processo que envolve geração, adoção, implementação e } \\
\text { incorporação de novas ideias, práticas ou artefatos dentro da } \\
\text { organização. }\end{array}$ \\
\hline Gonçalves e Gomes (1993) & $\begin{array}{l}\text { Inovações são mudanças nos processos de produção e nos modelos } \\
\text { dos produtos que sejam à base do progresso tecnológico. }\end{array}$ \\
\hline Tijssen (2002) & $\begin{array}{l}\text { É uma consequência das pesquisas básicas e invenções que são } \\
\text { inseridas no mercado. }\end{array}$ \\
\hline Byrd e Brow (2003) & $\begin{array}{l}\text { Inovação é uma combinação entre a criatividade e a tomada de } \\
\text { risco. }\end{array}$ \\
\hline Tidd; Bessant e Pavitt (2005) & $\begin{array}{l}\text { Nova tecnologia incorporada a produtos, que são diferentes } \\
\text { daqueles já produzida pela empresa. }\end{array}$ \\
\hline $\begin{array}{l}\text { Mcfadzean; O loughlin; Shaw } \\
\text { (2005, p. 3) }\end{array}$ & $\begin{array}{l}\text { "Um processo que fornece valor adicionado e um nível de novidade } \\
\text { para a organização e para seus fornecedores e clientes através do } \\
\text { desenvolvimento de novos procedimentos, soluções, produtos, e } \\
\text { serviços e também de novos métodos de comercialização". }\end{array}$ \\
\hline $\begin{array}{l}\text { Manual de Oslo (OECD, 2005, } \\
\text { p.46; FINEP, 2006, p.55) }\end{array}$ & $\begin{array}{l}\text { significativamente melhorado, ou um processo, ou um novo } \\
\text { método de marketing, ou um novo método organizacional nas } \\
\text { práticas de negócios, na organização do local de trabalho ou nas } \\
\text { relações externas". }\end{array}$ \\
\hline $\begin{array}{l}\text { Haines e Sharif (2006); MCT } \\
\text { (2002). }\end{array}$ & $\begin{array}{l}\text { Melhoria da gestão organizacional e de suas relações com o } \\
\text { ambiente externo e interno. }\end{array}$ \\
\hline (2007). & $\begin{array}{l}\text { Processo que inicia com a criação de uma ideia e finaliza com o } \\
\text { lançamento do produto no mercado. }\end{array}$ \\
\hline
\end{tabular}

Fonte: Autoria própria (2011)

Diante dos principais conceitos expostos, considerando a inovação como peça chave para promover o crescimento das empresas, faz-se necessário enxergar a mesma como um processo contínuo e gerenciável por ferramentas próprias, que asseguram ótimos resultados.

\subsection{Tipos de inovação}

Existem várias definições quanto aos tipos de inovação existente. Para efeito deste artigo, selecionaram-se as definições apresentadas pelo Manual de Oslo, que abrangem várias atividades das empresas, conforme segue:

- Inovações em produto: é a introdução de um beneficio ou serviço novo ou significativamente melhorado, em relação às suas características ou usos pretendidos. Inclui melhorias significativas nas edificações técnicas, componentes e materiais, software, interface com usuário ou outras características funcionais; 
- Inovações em processo: é a implementação de um novo ou significativamente melhorado processo produtivo (envolve técnicas, equipamentos e software utilizados para produzir benefícios ou serviços) ou entrega (interesse na logística da empresa e embalagem do equipamento, software e técnicas para fornecer materiais, alocar suprimentos na empresa, ou métodos de entrega de produtos acabados). Isto inclui modificações significativas em técnicas, equipamentos e/ou software;

- Inovações organizacionais: referem-se à implementação de novos métodos organizacionais, podendo ser mudanças em práticas de negócio, na organização do ambiente de trabalho, ou nas relações externas da empresa;

- Inovações em marketing: envolvem implementação de novos métodos de marketing. Podem incluir mudanças na aparência do produto e sua embalagem, na divulgação e distribuição do produto e em métodos para definir preços de benefícios e serviços. (OECD, 2005, p. 16-17).

Scherer e Carlomagno (2009, p. 12) ainda classificam a inovação quanto a sua intensidade, conforme segue:

\subsection{Práticas à inovação}

- inovações incrementais: são caracterizadas por um grau moderado de novidade e por ganhos significativos nos resultados. As inovações incrementais são impulsionadas pelo aumento da base de conhecimentos e da competência tecnológica anteriores e pela sua aplicação na obtenção de saltos de competitividade. Em geral, uma inovação incremental resulta de um processo estruturado de gestão da inovação a partir de ideias geradas internamente ou de necessidades detectadas do mercado. Podem-se destacar alguns exemplos, como a Coca-cola zero, o Check-In eletrônico das Cias aéreas, o iPod Shuffle da Apple, o sistema de Self Service de café da rede Starbucks. O que caracteriza tais iniciativas como inovações incrementais é o fato de serem uma continuidade de algo já existente.

- Inovações radicais induzem a grandes transformações nas regras competitivas, no processo produtivo, nos produtos e serviços ofertados, e nas preferências do consumidor. A inovação radical transforma as regras do jogo, altera o relacionamento com fornecedores, distribuidores e clientes, reestrutura a economia de determinados mercados, aposenta produtos vigentes e eventualmente cria categorias inteiramente novas de produtos. Inovações radicais envolvem mudanças significativas em produtos, processos e serviços que mudam os mercados e indústrias existentes ou criam outros absolutamente novos. O modelo "pré-pago" das empresas de telefonia, o fast-food de baixo preço da Habibs, a inigualável experiência de consumo do Cirque Du Soleil e o modelo de produção enxuto do Toyota são exemplos de inovações radicais.

Muitas são as razões pelas quais as empresas optam por investir em inovação. Independente do motivo, geralmente fazem-se necessárias algumas mudanças significativas no âmbito da empresa.

A seguir, elencou-se uma gama de práticas comuns às empresas que são consideradas altamente inovadoras:

- Cultura que apóia a criatividade e a participação dos colaboradores;

- Mobilização das equipes;

- Sistema de recompensa baseado em resultados;

- Entendimento do mercado e do consumidor;

- Monitoramento constante de tecnologias; 
- Mobilização de recursos externos;

- Gerenciamento de uma carteira de inovações equilibrada e baseada em critérios de priorização;

- Planejamento amplo e orientado à solução de problemas. (CORAL; GEISLER, 2008, p.17-19).

Essas práticas apontam a importância de se desenvolver um espaço motivado ao trabalho em equipe e a integração da tecnologia com todas as áreas da empresa. Faz necessário também, que a empresa esteja atenta ao seu entorno, de modo a buscar parcerias e "decifrar" o que o cliente deseja (pois nem sempre o cliente deixa explícito o que ele deseja).

\subsection{Barreiras à inovação}

Muitas variáveis podem afetar, diretamente ou indiretamente, os resultados esperados referentes ao processo inovação de uma empresa. Tais variáveis podem ser de ordem: econômica, cultural, corporativista e legal. (CORAL; GEISLER, 2008).

Essas variáveis podem fazer com que a empresa não consiga iniciar a etapa de inovação. Ou, caso consiga iniciar, não tenha "forças" para dar sequência ao processo num todo, ou ainda, obtenha um resultado negativo sobre os resultados esperados.

Nas palavras do Manual de Oslo (FINEP, 2006), essas barreiras podem estar relacionadas a um tipo específico de inovação ou a todos os tipos. Por exemplo, as barreiras relacionadas ao custo, podem interferir nas inovações de produto, processo, organizacional e marketing. Já as barreiras de ordem de mercado, podem afetar somente as inovações de produtos e marketing.

Além dessas barreiras, que já foram mencionadas, o poder decisório da empresa, a sua história e cultura e o ambiente externo, também são barreiras, que podem impedir a empresa de se obter resultados positivos em inovação. (CORAL e GEISLER, 2008).

Todas essas barreiras devem ser levadas em consideração quando do planejamento da gestão da inovação em âmbito empresarial.

\subsection{Ferramentas da inovação}

Existe uma gama de ferramentas desenvolvidas para gerenciar o processo de inovação nas empresas, conforme apresentadas no quadro 2.

Quadro 2: Ferramentas da inovação

\begin{tabular}{|l|l|l|}
\hline \multicolumn{1}{|c|}{ FERRAMENTA } & \multicolumn{1}{|c|}{ FOCO DE ATUAÇÃO } & \multicolumn{1}{c|}{ DESCRIÇÃO } \\
\hline Octógono da inovação & $\begin{array}{l}\text { Gestão da Inovação - } \\
\text { Diagnóstico e Planejamento }\end{array}$ & $\begin{array}{l}\text { Apresenta as 8 dimensões da } \\
\text { gestão da inovação. }\end{array}$ \\
\hline Radar da inovação & $\begin{array}{l}\text { Tipos de Inovação - Benchmark, } \\
\text { Diagnóstico e Planejamento }\end{array}$ & $\begin{array}{l}\text { Apresenta os 12 tipos existentes } \\
\text { de inovação. }\end{array}$ \\
\hline Cadeia de inovação & $\begin{array}{l}\text { Processo de Inovação - } \\
\text { Diagnóstico e Planejamento }\end{array}$ & $\begin{array}{l}\text { Apresenta os 4 estágios do } \\
\text { processo de inovação. }\end{array}$ \\
\hline Matriz de portfólio & $\begin{array}{l}\text { Gestão da Inovação - Novos } \\
\text { projetos e balanceamento de } \\
\text { iniciativas }\end{array}$ & $\begin{array}{l}\text { Apresenta a distribuição dos } \\
\text { projetos de inovação em função } \\
\text { de timming, risco e mercado. }\end{array}$ \\
\hline Innovation Scorecard. & $\begin{array}{l}\text { Gestão da Inovação - } \\
\text { Indicadores e Metas }\end{array}$ & $\begin{array}{l}\text { Apresenta o mapa de } \\
\text { indicadores para a gestão da } \\
\text { inovação. }\end{array}$ \\
\hline
\end{tabular}

Fonte: Scherer e Carlomagno (2009, p.74) 
Para efeito deste artigo, descreveu-se apenas a ferramenta que foi empregada neste estudo, a saber: Octógono da inovação.

Conforme, Scherer e Carlomagno (2009) o Octógono da inovação é uma ferramenta que auxilia tanto o diagnóstico do potencial de inovação quanto o desenho das práticas de gestão para melhorar seu desempenho. Estruturado em função de oito dimensões, apresenta os principais pontos a serem administrados para incrementar a produtividade da inovação - desde a estratégia até o processo de transformação de ideias em resultado. As oito dimensões da inovação que a ferramenta engloba são: estratégia de inovação; liderança para inovação; cultura de inovação; relacionamentos para inovação; estrutura para inovação; pessoas para inovação; processo de inovação; funding para a inovação. Como diferencial, apresenta um conjunto balanceado de aspectos necessários à gestão da inovação.

\section{METODOLOGIA}

\subsection{Classificação da pesquisa}

Esta pesquisa é classificada de natureza aplicada por gerar conhecimentos. De abordagem predominantemente quantiqualitativa por apresentar números, porcentagens e requerer interpretação dos fenômenos e a atribuição de significados. Com objetivo exploratório-descritivo visando proporcionar maior familiaridade com o problema com vistas a torná-lo explícito ou a construir hipóteses e descrever as características de determinada população ou fenômeno ou o estabelecimento de relações entre variáveis. E com seus procedimentos técnicos bibliográficos e estudo de caso, devido ter sido elaborada a partir de material já publicado, constituído principalmente de livros, artigos de periódicos e, atualmente, com material disponibilizado na Internet e por envolver o estudo profundo e exaustivo de um ou poucos objetos de maneira que se permita o seu amplo e detalhado conhecimento.

\subsection{Histórico da empresa}

A empresa estudada está a quase duas décadas atuando no mercado metalúrgico, situada na cidade de Curitiba no estado do Paraná. Trata-se de uma empresa de pequeno porte, que tem por objetivo atender as necessidades de seus clientes, quanto à qualidade dos produtos, atendimento e pontualidade na entrega. A empresa executa serviços nas áreas de caldeiraria, corte e pintura, e atende com máxima qualidade todas as exigências e necessidades de seus clientes.

Tem como missão atender as necessidades de seus clientes, com soluções para fabricação e serviços na área de metal, com excelência operacional, garantindo segurança e funcionalidade. Quanto aos valores, esta preza pela competência, compromisso, conhecimento, coragem, disposição, ética, honestidade, parceria, transparência e resultado na condução dos negócios.

O faturamento anual da empresa em 2010 teve um acréscimo de 13 \% em relação ao ano anterior.

O quadro funcional da empresa é composto por seis profissionais: um administrador, um engenheiro mecânico, três assistentes operacionais e uma secretária, ambos funcionários capacitados para atender plenamente as mais rígidas normas do mercado, oferecendo uma gama de serviços, para atender desde pequenas empresas até grandes corporações. 
Quanto às instalações, a empresa dispõe de um galpão com aproximadamente $250 \mathrm{~m}^{2}$ de área construída, onde dispõe de uma ampla área para fabricação, armazenagem de materiais e ferramentas e um escritório.

No tocante aos serviços oferecidos, a empresa oferece os serviços elencados no quadro 3.

Quadro 3: Serviços oferecidos pela empresa estudada

\begin{tabular}{|l|l|}
\hline \multicolumn{1}{|c|}{ ÁREA DE SERVIÇOS } & \multicolumn{1}{c|}{ DESCRIÇÃO } \\
\hline Caldeiraria & $\begin{array}{l}\text {-Bancadas industriais, estruturas metálicas, mezaninos, } \\
\text { grades e portões, pantográficas e projetos especiais; lotes } \\
\text { de peças seriadas; }\end{array}$ \\
\hline Corte: & - Corte plasma CNC \\
\hline Pintura: & - Convencional; eletrostática a pó. \\
\hline
\end{tabular}

Fonte: Autoria própria (2011)

Dispõe dos seguintes equipamentos: máquinas de soldas (MIG/MAG, TIG, eletrodo revestido e oxicombustível); ferramentas elétricas manuais; esmeril/policorte; corte plasma CNC; furadeira de bancada; compressor; equipamento de pintura (eletrostática e convencional); veículo leve e veículo utilitário.

Para divulgar seus serviços e interagir com seus clientes, a empresa dispõe de telefone, email e página eletrônica com fotos de alguns serviços realizados.

Desde a sua fundação até os dias atuais, a empresa tem se destacado quanto aos tipos de serviços prestados, pelo aprimoramento constante dos processos industriais, bem como pela inserção de novos materiais.

\subsection{Procedimentos da pesquisa}

A pesquisa foi realizada em julho de 2011, onde foram realizadas visitas para conhecimento do objeto de estudo e posterior definição e elaboração do instrumento de coleta de dados a ser empregado. Para a coleta de dados, o instrumento empregado foi à entrevista com um dos sócios da empresa e observação direta do ambiente estudado.

A entrevista ocorreu amparada com um roteiro estruturado, levando em consideração sete aspectos básicos, que fazem parte de qualquer estrutura organizacional, a saber: histórico, missão e valores; instalações; recursos humanos; serviços oferecidos, equipamentos; administração e comunicação.

Para visualizar os aspectos referentes às oito dimensões da inovação (octógono da inovação), a saber: liderança; estratégia; relacionamentos; cultura; pessoas; estrutura; processo e funding utilizou-se como ferramenta o Assessment da Inovação.

Esta ferramenta é composta por vinte e quatro afirmativas, agrupadas segundo as oito dimensões da inovação, sendo três afirmativas para cada uma destas dimensões, conforme segue:

- Liderança: afirmativas 9,13 e 16

- Estratégia: afirmativas 1, 6 e 17

- Relacionamento: afirmativas 15, 19 e 21

- Cultura: afirmativas 3, 7 e 22 
- Pessoas: afirmativas 4, 14 e 23

-Estrutura: afirmativas 2, 5 e 8

- Processo: afirmativas 11, 18 e 20

- Funding: afirmativas 10, 12 e 24.

Assim, pontuou-se a escala de 1 (discordo totalmente) a 7 (concordo totalmente) para cada uma das afirmativas, conforme escala, apresentada na figura 1 :

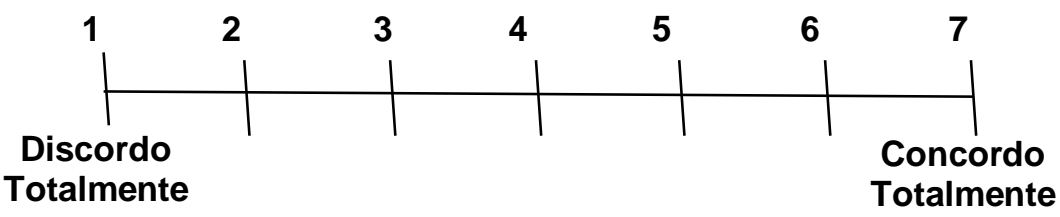

\begin{tabular}{|c|c|c|}
\hline No. & & \\
\hline 1 & $\begin{array}{l}\text { As nossas iniciativas de inovação estão logicamente alinhadas com a estratégia da } \\
\text { empresa. }\end{array}$ & 4 \\
\hline 2 & $\begin{array}{l}\text { As iniciativas altamente inovadoras são tratadas fora da estrutura organizacional principal, } \\
\text { em projetos específicos. }\end{array}$ & 4 \\
\hline 3 & $\begin{array}{l}\text { Disponibilizamos tempo, benefícios e incentivos (financeiros e não financeiros) para a } \\
\text { inovação. }\end{array}$ & 4 \\
\hline 4 & A necessidade de inovação é entendida por todos dentro da organização. & 4 \\
\hline 5 & $\begin{array}{l}\text { Nossa estrutura organizacional é flexível, com poucos níveis hierárquicos e muita } \\
\text { descentralização das decisões. }\end{array}$ & 4 \\
\hline 6 & Nossa empresa apresenta um foco claro no crescimento por meio da inovação. & 4 \\
\hline 7 & $\begin{array}{l}\text { Nossa empresa permite que todos corram riscos e cometam erros na busca de novas } \\
\text { soluções. }\end{array}$ & 4 \\
\hline 8 & As iniciativas e atividades de inovação possuem uma coordenação definida. & 4 \\
\hline 9 & As lideranças da empresa têm clareza sobre o conceito e a importância da inovação. & 4 \\
\hline 10 & Temos um orçamento específico para os projetos de inovação. & 4 \\
\hline 11 & Utilizamos ferramentas de gestão de projetos para conduzir as iniciativas de inovação. & 4 \\
\hline 12 & $\begin{array}{l}\text { As novas ideias são avaliadas conforme medidas de desempenho que levem em } \\
\text { consideração os riscos e incertezas existentes. }\end{array}$ & 4 \\
\hline 13 & $\begin{array}{l}\text { O desempenho das lideranças é avaliado com métricas específicas relacionadas a sua } \\
\text { atuação no processo de gestão da inovação. }\end{array}$ & 4 \\
\hline 14 & $\begin{array}{l}\text { Os conhecimentos e ferramentas necessárias para inovar são conhecidos de todos dentro } \\
\text { da organização. }\end{array}$ & 4 \\
\hline
\end{tabular}




\begin{tabular}{|c|c|c|}
\hline 15 & $\begin{array}{l}\text { Utilizamos nossas redes de clientes, fornecedores e até concorrentes para gerar e refinar } \\
\text { novas ideias. }\end{array}$ & 4 \\
\hline 16 & As lideranças dedicam tempo e atenção ao acompanhamento dos projetos de inovação. & 4 \\
\hline 17 & Existem temas, objetivos e metas definidos para a inovação. & 2 \\
\hline 18 & Avaliamos sistematicamente os resultados das iniciativas de inovação. & 4 \\
\hline 19 & $\begin{array}{l}\text { Conhecemos profundamente as necessidades reveladas e não reveladas de nossos clientes } \\
\text { e não clientes. }\end{array}$ & 2 \\
\hline 20 & Dispomos de um processo estruturado para geração e seleção das melhores ideias. & 4 \\
\hline 21 & $\begin{array}{l}\text { Temos um processo sistemático para acompanhamento de novas tendências de mercado e } \\
\text { tecnológicas. }\end{array}$ & 2 \\
\hline 22 & Utilizamos mecanismos de comunicação para fomentar a inovação na empresa. & 4 \\
\hline 23 & Nossa equipe apresenta alta diversidade de conhecimentos, valores, carreira e interesses. & 4 \\
\hline 24 & $\begin{array}{l}\text { Buscamos recursos financeiros para inovação em diferentes fontes (capital de risco, } \\
\text { órgãos de governo, parceiros etc..). }\end{array}$ & 4 \\
\hline
\end{tabular}

Figura 1: Perguntas do Assessment da Inovação

Fonte: Scherer e Carlomagno (2009, p.140 - 141).

Depois de atribuído a pontuação para cada uma das afirmativas conforme a escala é tirada a média das três respostas, referente a cada uma das dimensões da inovação. A média máxima é 7,0 .

Com base nesta média, o Assessment da Inovação deu origem a um gráfico radar, que será apresentado no tópico a seguir, denominado de: discussão dos resultados, seguido da análise de cada uma de suas dimensões.

\section{DISCUSSÃO DOS RESULTADOS}

O gráfico radar, conforme mostra a figura 2, obtido por meio do Assessment da inovação, apresenta o desempenho e as práticas da empresa estudada em relação às oito dimensões da inovação.

Assim, a empresa estudada obteve 4 pontos de 7, conforme escala aplicada, nas seguintes dimensões: liderança, funding, processo, estrutura, pessoas e cultura. E obteve-se 3,83 em estratégia e 2,67 em relacionamentos. 


\section{Innovation Assessment}

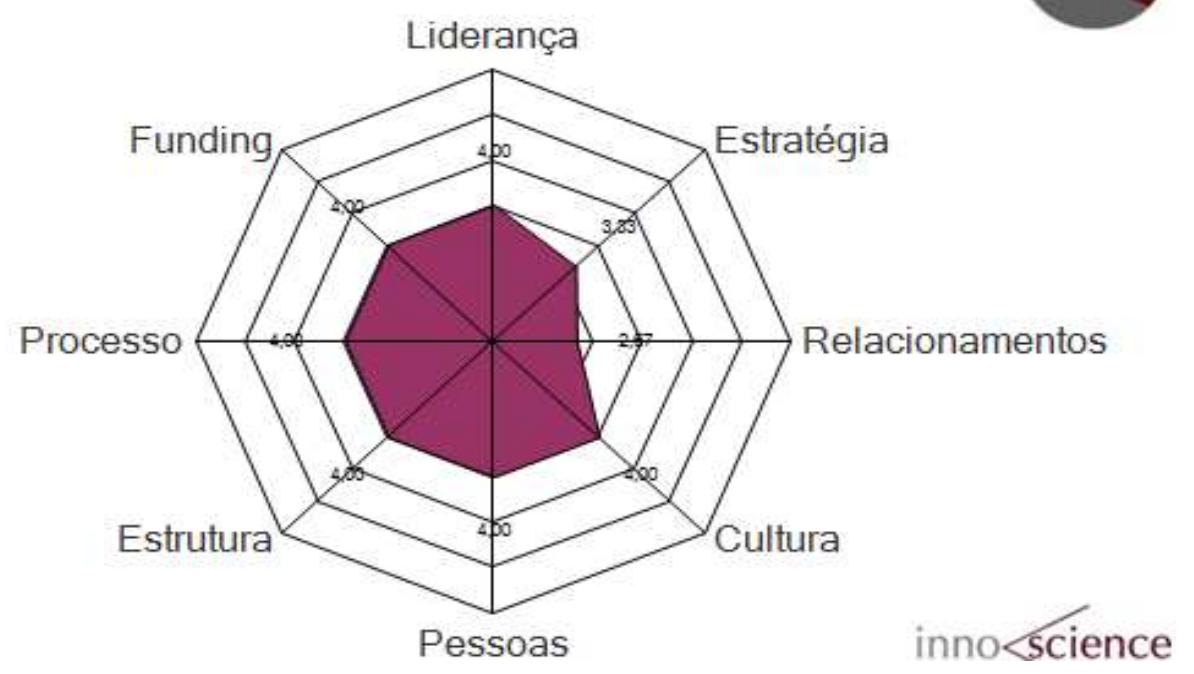

Figura 2: Gráfico radar da inovação da empresa estudada gerado pelo Assessment da Inovação Fonte: gerado por meio do Assessment da Inovação

Na dimensão liderança, a pesquisa aponta que a empresa estudada tem clareza sobre o conceito e a importância da inovação. Estes funcionários realizam cursos do SEBRAE, MBAs e entre outros. Cabe ressaltar que um dos funcionários está cursando mestrado em engenharia mecânica, na área de concentração de fabricação mecânica. Porém, por não despender de muitos recursos financeiros, muitas coisas que são vistas nos cursos não são aplicadas na empresa. O desempenho das lideranças não é mensurado com métricas específicas relacionadas à sua atuação no processo de gestão da inovação. Somente quando da execução de um projeto de inovação de curto prazo, as lideranças dedicam tempo e atenção para o acompanhamento desses projetos. Não existe um tempo destinado especificamente para o planejamento da gestão da inovação na empresa.

Quanto à dimensão Funding, os dados mostram que, a empresa tem consciência de que para inovar, a mesma precisa investir em pesquisa e em desenvolvimento. Porém, como se trata de uma empresa de pequeno porte, esta empresa investe $5 \%$ da receita líquida em projetos de pesquisa e desenvolvimento que visam retorno imediato. Já para os projetos de inovação, cujo retorno é a médio e longo prazo, a empresa recorre a financiamentos em instituições financeiras, em empresas parceiras e novos sócios. Para selecionar os projetos de inovação que serão desenvolvidos, a empresa leva em consideração os riscos e as incertezas existentes, mediante reuniões semanais, onde as novas ideias são discutidas, sob o foco da demanda de produção e satisfação do cliente. A empresa está investindo 15 \% de sua receita líquida em infraestrutura.

No que se refere à dimensão processo, constatou-se que, a empresa possui um método dinâmico e interdisciplinar de trabalho, no qual as várias áreas: produção, finanças, recursos humanos e marketing se reúnem constantemente para avaliar os avanços e trocar sugestões. A empresa não dispõe de um software de gestão de projetos para direcionar as iniciativas de inovação. As iniciativas de inovação são conduzidas por meio de planilhas eletrônicas elaboradas internamente. A geração e seleção das melhores ideias não ocorrem de forma estruturada, essas são discutidas nas reuniões semanais. Assim, pode-se inferir que a empresa não possui um 
processo formal e estruturado de inovação, mas procura a partir de tendências de mercado desenvolver soluções inovadoras. Com isso, a empresa obteve $65 \%$ de sucesso com as iniciativas de inovação nas áreas de produção, finanças, recursos humanos e marketing .

Já a dimensão estrutura, a pesquisa revelou que os funcionários recebem treinamento técnico, operacional e motivacional para atender os clientes com qualidade e eficiência. A estrutura organizacional é flexível, com poucos níveis hierárquicos. As iniciativas e atividades de inovação ficam sob a responsabilidade do administrador da empresa.

Na dimensão pessoas, a pesquisa aponta que a necessidade de inovação da empresa é entendida apenas pelo administrador e pelo engenheiro mecânico, bem como as ferramentas e conhecimentos necessários para a inovação. Apenas esses dois profissionais citados participam de cursos e treinamentos com o enfoque para a inovação.

No tocante a dimensão cultura, a empresa não dispõe de uma equipe de criatividade. Hoje sua cultura está voltada apenas a satisfação do cliente. A empresa não dispõe de uma política ou programa formalizado de geração e recompensas de ideias, que poderão gerar inovações por parte dos funcionários. Por ser uma pequena empresa, esta não dispõe de recursos financeiros para aceitas riscos e erros. Os projetos de inovação são cautelosamente analisados e quando decidido entrar em execução, este é divulgado a todos os funcionários por meio de cartazes e emails. O cronograma do projeto bem como suas etapas realizadas podem ser visualizadas por todos os funcionários da empresa, pois este fica exposto em um quadro e é apresentado a todos nas reuniões semanais.

$\mathrm{Na}$ dimensão relacionamentos, constatou-se que o canal de comunicação da empresa com o cliente, hoje é o email. A empresa não realiza uma pesquisa de mercado para conhecer as necessidades de seus clientes reais e potenciais, falta ainda realizar uma rede de clientes, fornecedores e até concorrentes para promover a geração de novas ideias. Falta também, a empresa realizar uma pesquisa de modo a acompanhar as novas tendências e tecnologias de mercado.

E por fim, na dimensão estratégia, verificou-se que as iniciativas de inovação não estão alinhadas com a estratégia da empresa. O que ocorre são iniciativas isoladas de inovação. A empresa pretende ter um crescimento, bem como expandir suas operações e serviços para conquistar novos clientes, porém não tem um planejamento documentado com tais metas.

Após, análise do gráfico radar obtido, sugere-se que a empresa estudada contrate um engenheiro de produção para se reorientar com urgência nas dimensões "estratégia" e "relacionamentos" e organizar, sistematizar ou introduzir novas atividades para consolidar seu processo de Gestão da inovação, reduzindo custos, aumentando a produtividade e empregabilidade, tornando-se mais competitiva e assim, obtendo uma fatia maior no mercado metalúrgico.

\section{CONSIDERAÇÕES FINAIS}

Este artigo apresenta um diagnóstico da gestão da inovação em uma empresa de pequeno porte no segmento metalúrgico. Para tanto, buscou-se obter dados para a discussão através da realização de entrevistas e observação do ambiente, a fim de se elaborar análises do ambiente estudado. 
A justificativa deste estudo está alicerçada na ideia de que a inovação é o elemento chave para garantir as empresas resultados frutíferos, com base na afirmação de Scherer; Carlomagno $(2009$, p. 2) de que inovar "significa buscar novos resultados através de novas estratégias, de novas ideias, de novas ações".

Nesta ótica, a empresa estudada tem clareza da importância da inovação para sua expansão no mercado. No entanto, por não despender de muitos recursos financeiros e por falta de apoio, a empresa estudada tem medo de ousar.

Com este estudo, pode-se constatar que no momento, a empresa estudada está mais focada em desenvolver sua infraestrutura, investindo assim, $15 \%$ de sua receita líquida na compra de máquinas, ferramentas e equipamentos mais sofisticados, na ampliação da área para fabricação e armazenagem de materiais e em campanhas publicitárias.

Em segundo plano, pode-se constatar que a empresa estudada almeja apostar em inovação a fim de expandir-se no mercado. Para tanto, a empresa está buscando parcerias, novos sócios e apoio financeiro em órgãos governamentais, vislumbrando desenvolver projetos de inovação a curto, médio e longo prazo.

Esta constatação é positiva, pois com a ampliação da área para fabricação e com a compra de máquinas, ferramentas e equipamentos mais sofisticados, os projetos de inovação terão um ambiente mais propício e melhores condições para serem desenvolvidos.

Mas, isso por si só não será suficiente para a empresa estudada obter melhores resultados e aumentar sua fatia no mercado metalúrgico. Pois, como foi diagnosticada, a referida empresa necessita reestruturar processos, reorientar as dimensões "estratégia" e "relacionamentos", organizar e introduzir novas ações para efetivar seu processo de Gestão da inovação, por estes motivos, recomenda-se a contratação de um engenheiro de produção para atuar neste contexto.

\section{REFERÊNCIAS BIBLIOGRÁFICAS}

1. BYRD, J. ; BROWN, P. L. The innovation equation: building creativity and risk talking in your organization. San Francisco: Jossey- Bass, 2003.

2. CORAL, Eliza; GEISLER, Lisiane. Motivação para a inovação. In: CORAL, Eliza; OGLIARI, Andre; ABREU, Aline França de. Gestão integrada da inovação: estratégia, organização e desenvolvimento de produtos. São Paulo: Atlas, 2008. p. 14 - 27.

3. Organização para a inovação. In: CORAL, Eliza; OGLIARI, Andre; ABREU, Aline França de. Gestão integrada da inovação: estratégia, organização e desenvolvimento de produtos. São Paulo: Atlas, 2008. p. $45-82$.

4. FINEP - FINANCIADORA DE ESTUDOS E PROJETOS. Manual de Oslo: proposta de diretrizes para coleta e interpretação de dados sobre inovação tecnológica. Brasília, 2006.

5. GONÇALVES, J. E. L.; GOMES, C. A. A tecnologia e a realização do trabalho. Revista de Administração de empresas, São Paulo, n. 1, v. 33, janeiro-fevereiro, 1993, p. 106-121.

6. HAINES, J. D. ; SHARIF, N. M. A framework for managing the sophistication of the components of technology for global competition. Competitiveness Review, v.16, n.2, p. 106-121, 2006. 
7. LAKEMOND, N. et al. Interfaces between technology development, product development and production: critical factors and a conceptual model. International journal of Technology Intelligence and Planning, v.3, n.4, p. 317-330, 2007.

8. MAÑAS, A. V. Gestão de tecnologia e inovação, São Paulo: Érica, 2001, 176p.

9. MCFADZEAN, E. ; O'LOUGHLIN, A. ; SHAW, E. Corporate entrepreneurship and innovation part. 1: the missing link. European Journal of Innovation Management, v. 8, n.3, p.350-372, 2005.

10. MINISTÉRIO DA CIÊNCIA E TECNOLOGIA. Livro branco: ciência, tecnologia e inovação. Brasília: resultado da Conferência Nacional de ciência, tecnologia e inovação, 2002.

11. MONTANHA JUNIOR et al. Importância, definições e modelos de inovação. In: CORAL, E. ; OGLIARI, A. ; ABREU, A. F. In: Gestão integrada da inovação: estratégia, organização e desenvolvimento de produtos. São Paulo: Atlas, 2008. p. 01 - 13.

12. OECD - ORGANIZATION FOR ECONOMIC CO-OPERATION AND DEVELOPMENT. Oslo manual : guidelines for collecting and interpreting innovation data. 2005. 3. Ed. European Commission: OECD. Disponível: <www.oecd.org> . Acesso em: 15 out. 2011.

13. ROBERTS, E. B. Managing invention and innovation. Research Technology Management, v. 50, n.1, p. 35-54, 2007.

14. SCHERER, Felipe Ost; CARLOMAGNO, Maximiliano Selistre. Gestão da inovação na prática: como aplicar conceitos e ferramentas para alavancar a inovação. 1. ed. São Paulo: Atlas, 2009.

15. TIDD, J. ; BESSANT, J.; PAVITT, K. Managing innovation - integrating technological, market and organization change. 3. Ed. John Wiley \& Sons, 2005.

16. TIJSSEN, R. J. W. Science dependence of technologies: evidence from inventions and their inventors. Research Policy, v.3, n.4, p. 509-526, 2002.

17. VAN DE VEN et al. Research on the management of innovation: the Minnesota studies. New York: Ballinger/Harper \& Row, 1989. 